\title{
SMART SUPPLY CHAIN - CHALLENGES OF INFORMATION-DRIVEN MANAGEMENT
}

\author{
MARZENA FRANKOWSKA, ${ }^{1}$ KATARZYNA NOWICKA ${ }^{2}$ \\ ${ }^{1}$ University of Szczecin, POLAND \\ e-mail: marzena.frankowska@wzieu.pl \\ ${ }^{2}$ Warsaw School of Economics, POLAND \\ e-mail: katarzyna.nowicka@sgh.waw.pl
}

RECEIVED
ACCEPTED
JEL
CLASSIFICATION

KEYWORDS smart supply chain, Internet of Things, Big Data, information-driven supply Chain

ABSTRACT

27 November 2017

5 January 2018

014, O31, 033, Q55
Smart Supply Chain is the answer to challenges of the Fourth Industrial Revolution (Industry 4.0). It uses features, mechanisms and technologies essential to integrate the whole system, that is Smart Industry, in an end-to-end perspective, namely taking into account all links that cooperate as part of delivering values to customers. As part of a Smart Supply Chain, all its components, namely factories, people, machines, products and service design, manufacture and delivery systems cooperate in order to satisfy customers' needs as effectively and quickly as possible. The basis for building new generation supply chains is the possibility to link data and information from different sources. The aim of this article is to present the concept of the Smart Supply Chain in the context of challenges related to the management of information flow. Apart from the discussion of the concept itself and the meaning of information in the Smart Supply Chain, main supporting technologies have been presented. To reach the objectives set in the research, a review of subject literature has been made and the latest research results undertaken by Sapio Research on behalf of Zetes Corporate, concerning the assessment and challenges related to end-to-end supply chain information requirements and current operational reality, have been used.

\section{Introduction}

The global economy is entering the fourth era of industrial revolution, the functioning of which is based on Cyber-Physical Systems (CPS), integrating factories, products and customers by including them in Smart Supply Chains. The aim of this article is to present the concept of the Smart Supply Chain in the context of challenges related to the management of information flow. The new generation of supply chains more than hitherto appreciates 
the role of modern technologies and full access to information on all aspects of functioning of a supply chain in order to increase efficiency and competitive advantage. Recent technological progress makes it possible to both generate and exchange data essential to manage a supply chain in an intelligent manner. Thus, the article seeks to answer the following research questions:

- What is the relevance of information in the functioning of the Smart Supply Chain?

- Which technologies support the development of the Smart Supply Chain?

- Which is the state of progress of implementation of the Smart Supply Chain, measured by visibility and the degree of utilization of information in the supply chain?

To reach the objectives set in the research, a review of subject literature has been made and the latest research results undertaken by Sapio Research on behalf of Zetes Corporate, concerning the assessment and challenges related to end-to-end supply chain information requirements and current operational reality, have been used.

\section{The essence of the concept of the Smapt Supply Chain}

At present, various dimensions of the concept of the so-called Fourth Industrial Revolution are analyzed in the subject literature and economic realities. Its understanding goes beyond the subject of using advanced technologies in manufacturing processes. What is more, it is no longer limited to issues related to robotization and automation of a single manufacturing facility, but includes also an integration of Core Functions with supply chains as part of which design, manufacture and supply of intelligent products to consumers takes place. Therefore, the idea of Smart Industry is made up of four main components, namely Smart Factory cooperating within the framework of a Smart Supply Chain based on Smart Technologies in order to manufacture and supply Smart Products and Services (Frankowska, Nowicka, 2018). An important response to these conditions is the need to change an approach to developing the supply chain. Companies which have discerned the relevance of changes occurring in the economic environment more and more often migrate their operations, processes (planning, purchases, manufacturing, deliveries and returns) - and the megaprocess of supply chain management itself to the virtual world. As a result, Smart Supply Chains are created, which are defined by Wu et al. as the new interconnected business system which extends from isolated, local, and single-company applications to supply chain wide systematic smart implementations (Wu, Yue, Jin, Yen, 2016). Thus, Smart Supply Chain is a system which ensures full interoperability and which uses the potential of technologies, namely loT, Cloud Computing, 3D printing, Big Data and big data analytics, artificial intelligence, automation or robotization. Such an ecosystem of technologies and an appropriate use of data analytics makes it possible to take decisions in near real-time of events taking place in the physical world at various levels of the supply chain. This requires integration processes which consist of (Wang, Wan, Li, Zhang, 2016; PwC, 2016):

a) vertical integration, which involves internal processes of a company, ranging from design and purchase to customer and after-sales services;

b) horizontal integration, which takes into account collaboration with suppliers, customers and cooperators in the value chain. 
Smart Supply Chains have a set of characteristics which distinguish them. These include (Wu et al., 2016):

a) instrumented: information in the next generation supply chain is overwhelmingly being machine-generated, for example, by sensors, RFID tags, meters, and many others;

b) interconnected: the entire supply chain, including business entities, and assets, IT systems, products, and other smart objects are all connected in a smart supply chain;

c) intelligent: smart supply chains make large-scale optimal decisions to optimize performance;

d) automated: smart supply chains must automate much of its process flows by using machines to replace other low-efficiency resources including labor;

e) integrated: supply chain process integration involves collaboration across supply chain stages, joint decision making, common systems, and information sharing; and

f) innovative: innovation is the development of new values through solutions that meet new requirements, inarticulate needs, or even existing needs in better ways.

Companies integrated as part of supply chains also discern the potential resulting from utilization of modern technologies in flows management. As a result, they migrate from classical models based on sequential transactions between particular links to solutions utilizing digital technologies in management of particular processes of the chain, or a network, of supplies. Progressing digitalization contributes to the development of Smart Supply Chains.

\section{Generating and exchanging information in a Smapt Supply Chain}

One of the most important characteristics of Smart Supply Chain is being instrumented. The information plays crucial role in enabling supply chain competitiveness. Data is processed into the information on the basis of which decisions are made. Therefore the relevant data delivered in a real time to the right partner is the most important aspect of Smart Supply Chain development.

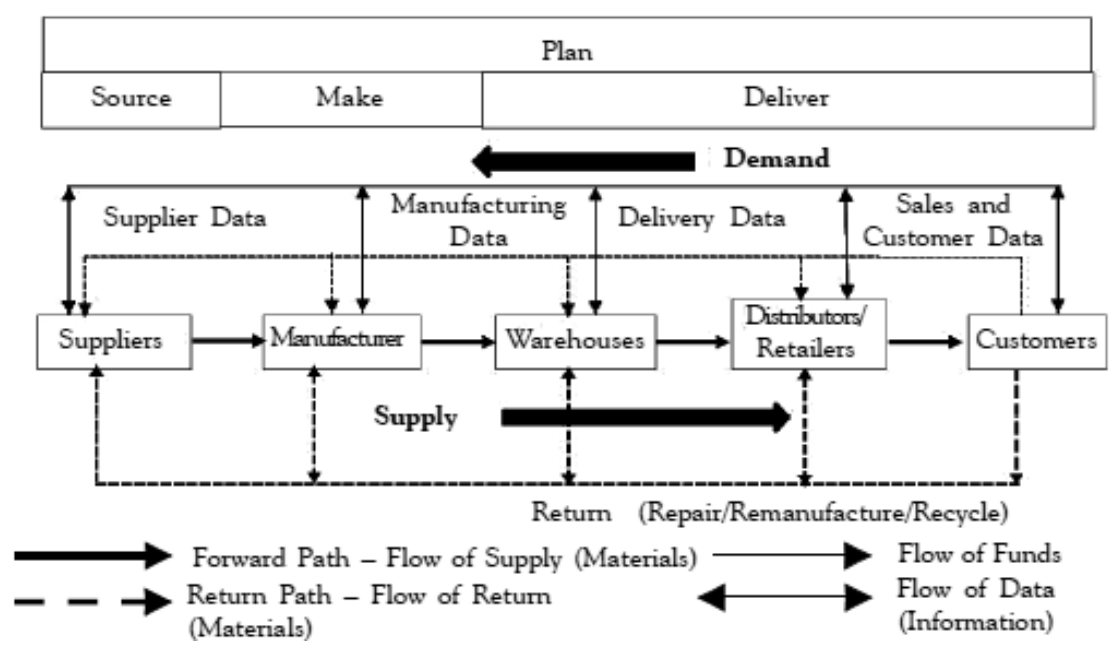

Figure 1. Information-driven Supply Chain

Source: Biswas, Sen (2016). 
Information in the context of supply chain management includes i.e. customer information, sales information, market and competitor information, product and service level requirement, promotion/brand information, demand forecasting, inventory, capacity utilization, process planning and control information, skill inventory, human information, sourcing/vendor information, networking information, logistics, warehouse planning, pricing and fund flow/working capital information. All these information is preliminary initiated at customer end which flows through subsequent stages to the supplier end. The data being generated at subsequent stages are classified into four categories - supplier data, manufacturing data, delivery data and sales and customer data. The structure of information-driven supply chain is shown on Figure 1 (Biswas, Sen, 2016).

All these data creates new competitive weapon that role can never be over emphasized in the context of supply chain. However it also creates a great amount of data that should be stored, processed and distributed between supply chain partners. It is important due to the fact, that access to the data and sharing information between partners in Smart Supply Chain is a main success factor for gaining on competitiveness. It should be also underlined that it can be based on the data generated by any object in the supply chain. The adoption of advanced information systems in supply chains is crucial for sharing and analysing large amounts of data among multiple actors (Urciuoli, Hintsa, 2016). To make it possible the adequate technologies should be revised and implemented within supply chain partners.

\section{The evolution of technologies conditioning the development of the Smart Supply Chain}

As has already been mentioned, sole use of the Internet or robotization of manufacturing processes is at present not enough to maximize the benefits resulting from the implementation of modern technologies. In the Smart Supply Chain, which is information-driven, there is a need to combine solutions and utilize of technologies in a wider spectrum. In the subject literature there is no unanimity concerning which technologies are main enabling technologies supporting intelligent industry and intelligent supply chains. However, it is appropriate to assume that the basis for any development is the development of the Internet and the capability to process data in the cloud, including Big Data Analytics. The Internet of Things (IoT), often extended to the concept of the Internet of Everythings (loE), plays a particularly significant role in the issues of access to information on an unprecedented scale. IOT is a network of people, processes, data, devices, applications and things connected to the Internet. Thanks to these connections, material and social elements connected to each other create loT network, collecting and exchanging data and interacting with each other (Lee, Lee, 2015). CPS are created and they include networks, software and the capacity to process data. Cloud computing, on the other hand, is both a set of information and communication technologies and a data processing model in the form of services, the development of which has redefined the manner in which IT solutions are provided by suppliers and purchased, used and financed by recipients (Dziembek, 2016). In literature, the terms processing in the cloud and Big Data are combined more than once. This results from the fact that cloud computing provides access to unlimited resources on demand, which is related to the necessity to process an increased amount of data (Lee, Lee, 2015). Big data operates on the basis of a current analysis of increasing very big collection of data in real time, thanks to which analyses are always up-to-date. Technological process is also related to the development of robotics. In the subject literature there are numerous definitions of the term „robot”, which is connected to considerable progress in this field. Taking into account the manner of programming and the possibility of communication of a robot with its environment, four generations of robots can be distinguished: taught robots, learning robots, intelligent robots and integral robots. 
An important direction of development which has been taken by all leading robot manufacturers is the capacity of a robot to cooperate with a human being. Collaborative robots, also called co-bots, are being developed and they change the manner in which the role of robotics is perceived in industry. In the main traditional approach the aim was to keep people away from dangers in the course of a production process. At present, the requirements are much more demanding, and they are related to the precision and variety of conducted work. That is why robots are used in technological operations, including installation, packaging, and palletization as well as in transport. It is also worth drawing attention to future technologies which, along with technological progress, will be used more commonly in the Smart Supply Chain. These include 3D printing directly liked to Additive Manufacturing (AM). AM includes also rapid prototyping techniques, which are employed as a low-volume manufacture and manufacture of single products, spare parts and untypical elements (Cichoń, Brykalski, 2017). Reference should also be made to Augmented Reality (AR). This is an area of computer science which deals with connecting the real world with visual elements, generated by means of computer graphics. Even though AR is not yet used on a wider scale, the following of its applications are possible for now: positioning and relocation of heavy objects, air, road and water traffic control, customs and border control, as well as applications in warehouse management.

The range of application of described technologies in the Smart Supply Chain varies, but their common feature is the capability to use information as a basis of conducted actions and processes.

\section{Supply Chain Visibility evaluation}

The complexity of supply chains compounded by trust issues in many industry traditionally impede the flow of information between trading partners. Therefore companies are facing a number of challenges to remain competitive. According to research undertaken by Sapio Research on behalf of Zetes (2017) during August 2017, across Europe and South Africa (respondents were senior executives within a range of manufacturing sectors) manufacturers need to improve speed, accuracy and agility in the end-to-end supply chain. There is a must for more visibility within the supply chain flows.

$89 \%$ of respondents perceive a single view of the supply chain as a key priority, yet $70 \%$ still have no end-toend visibility. It is due to the fact that information is not harmonised - only a third of manufacturers find it easy to aggregate information across supply chain. As much as $67 \%$ are still struggling to share key information between own departments. At the same time $80 \%$ of respondents say that it is of significant importance to have visibility of risks affecting supply (this has been achieved by just one quarter of them). Additionally, $75 \%$ want visibility of all events affecting the inbound flow of goods from suppliers (this has been achieved by only $29 \%$ ). Constraints in achieving an aggregated view are the following:

- poor quality or incomplete information from suppliers $(70 \%)$,

- non-collection of key data (60\%),

- securing information from non-integrated systems $(60 \%)$,

- incomplete or poor information from customers $(60 \%)$.

Many companies still use outdated methods of cooperation an information sharing. $60 \%$ of them still use email to secure information from different stages of the supply chain, $37 \%$ EDI, $36 \%$ telephone and $21 \%$ fax. While the use of the loT - by $28 \%$ - demonstrates a growing trend towards digitisation, it seems to be insufficient to be able to gain competition. As much as $68 \%$ of organisations cannot provide decision makers with access to the information required to make informed business decisions. To solve the problem of lack of visibility in the supply 
chains manufacturers are considering real-time data connectivity (38\%), supplier collaboration (38\%), supplier performance monitoring (35\%) and predictive alerts to mitigate disruption (34\%). Thus the key priorities for real-time visibility of information are transport from suppliers $(76 \%)$, stock levels held by clients $(73 \%)$, demand forecasts from clients (71\%) and manufacturing volumes across plants within the organisation $(71 \%)$.

It should be also underlined that essential understanding of Digital Supply Chain is very low $(29 \%$ of respondents understand this issue) and just $15 \%$ are implementing this solution and expect them to become the norm for the business in the next five years.

\section{Conclusions}

Nowadays the digital technology solutions might serve as an almost perfect enabler for solving complexity and visibility challenges in supply chains. Additionally sensors, computing power and connectivity are becoming cheaper, smaller and more powerful. Therefore many companies leverage these advanced technologies to remotely access machine data to schedule maintenance operations, optimize the daily performance of assets and help customers who experience problems with their products (Hoberg, Herdmann, 2018). With loT technology, transparency and visibility across the entire supply chain is now possible. loT is able to real-timely monitor the process of a supply chain execution and also to further improve the efficiency and effectiveness of supply chain. This also enables manufacturers to change their business models and types of interactions with other partners in the supply chain. Smart Supply Chains are the next-generation supply chains that are based on sharing information and digital technology. They are instrumented, interconnected, intelligent, automated, integrated and innovative. Based on technology they enable end-to-end visibility in the supply chain.

However one of the recent study shows that a broad range of challenges that manufacturing companies facing in terms of improving visibility exist. Smart Supply Chain is still the future project for most of the companies. At the same time, unquestionably, this is the most important direction for further development.

\section{References}

Biswas, S., Sen, J. (2016). A Proposed Architecture for Big Data Driven Supply Chain Analytics. The IUP Journal of Supply Chain Management, XIII (3), 7-33.

Cichoń, K., Brykalski, A. (2017). Zastosowanie drukarek 3D w przemyśle. Przegląd Elektrotechniczny, 3, 156-158.

Dziembek, D. (2016). Cloud Computing - charakterystyka i obszary zastosowań w przedsiębiorstwach. In: R. Knosala (ed.), Innowacje w zarządzaniu i inżynierii produkcji (pp. 725-739). Opole: Oficyna Wydawnicza Polskiego Towarzystwa Zarządzania Produkcja.

Frankowska, M., Nowicka, K. (2018). Zarzązanie łańcuchem dostaw w dobie Smart Industry. Gospodarka Materiałowa i Logistyka, 3.

Hoberg, K., Herdmann, Ch. (2018). Get Smart (about replenishment): Smart replenishment systems that continuously track inventories at the point-of-consumption (POC) are powerful technologies that can radically change supply chains. Supply Chain Management Review, 1 (22), 12-19.

Lee, I., Lee, K. (2015). The Internet of Things (IOT): Applications, investments, and challenges for enterprises. Business Horizons, 58, $431-440$.

PwC (2016). Przemysł 4.0 czyli wyzwania współczesnej produkcji, p. 12.

Urciuoli, L., Hintsa, J. (2017). Adapting supply chain management strategies to security-an analysis of existing gaps and recommendations for improvement. International Journal of Logistics Research and Applications, 20 (3), 276-295.

Wang, S., Wan, J., Li, D., Zhang, Ch. (2016). Implementing Smart Factory of Industrie 4.0: An Outlook. International Journal of Distributed Sensor Networks, 7 (16), 1-10. 
Wu, L., Yue, X., Jin, A., Yen, D.C. (2016). Smart supply chain management: a review and implications for future research. The International Journal of Logistics Management, 2 (27), 369-400.

Zetes (2017). Manufacturers want supply chain visibility and collaboration; what's holding them back? Brussels: Zetes Corporate.

Cite this apticle aS: Frankowska, M., Nowicka, K. (2018). Smart Supply Chain - challenges of information-driven management. European Journal of Service Management, 1 (25), 91-97. DOI: 10.18276/ejsm.2018.25-11. 